\title{
Corneal infiltration after recurrent corneal epithelial erosion
}

\author{
A C W Ionides, S J Tuft, V M G Ferguson, M M Matheson, P G Hykin
}

\begin{abstract}
Aims-To describe the clinical features of patients with a history of recurrent corneal epithelial erosion who develop acute corneal infiltration.

Methods-The records were reviewed of patients who had previously been examined and treated for recurrent corneal epithelial erosion and who presented again with signs suggestive of a microbial keratitis.

Results-11 patients were described; one patient presented with similar signs on two occasions. There was typically a paracentral epithelial defect $>2 \mathrm{~mm}$ in diameter with an associated stromal infiltrate and an intense anterior uveitis. Three patients had a hypopyon, and four developed a subepithelial ring infiltrate. Samples were taken for microscopy and bacterial culture, with a positive isolate from two of 12 episodes (16\%). Treatment with topical antibiotics and topical corticosteroid resulted in rapid reepithelialisation and a reduction of inflammation. There was good visual outcome for all eyes, with a recurrence or symptoms of epithelial erosion in only one eye after a mean follow up period of 18 months.

Conclusions-Corneal infiltrates are an uncommon complication of recurrent corneal epithelial erosion. Despite the intensity of the infiltration the majority are culture negative using established techniques. There is typically rapid resolution and a good visual outcome, with a tendency for the episode to mark the end of further symptoms of epithelial erosion. (Br F Ophthalmol 1997;81:537-540)
\end{abstract}

Hospital, City Road, London EC1V 2PD

A C W Ionides

S J Tuft

V M G Ferguson

P G Hykin

Department of Pathology, Institute of Ophthalmology, Bath Street, London EC1V 9EL

M M Matheson

Correspondence to: Mr S J Tuft, Moorfields Eye Hospital, London EC1V 2PD.

Accepted for publication 11 March 1997 be an epithelial attached epithelium, while between attacks there may be a microcystic epitheliopathy, with linear or geographic changes at the level of the epithelial basement membrane. In the majority of cases the acute symptoms rapidly settle after prophylactic treatment with topical antibiotic, cycloplegia, and padding. Debridement of the loose epithelium hastens resolution of the acute episode but has not been shown to prevent recurrences. However, the use of an ointment at night prevents or reduces the severity of recurrences in most cases and is as effective as hypertonic saline ointment. ${ }^{89}$

Complications of RCE are infrequent, but include anterior uveitis and stromal scarring. Acute stromal infiltrates are uncommon and suggest a secondary microbial keratitis. Shoch et al described stromal infiltrates in five patients who had RCE and anterior basement membrane dystrophy but with negative corneal cultures in the three cases that were investigated. ${ }^{10}$ In contrast, Luchs et al reported five patients who developed an infiltrate associated with an epithelial erosion with bacteria isolated from four of the five eyes. ${ }^{11}$ In a prospective casualty based study of 117 patients presenting with a history of RCE there was only one case with a corneal infiltrate and no organism was isolated. ${ }^{12}$ We describe a further 11 patients who were documented to have RCE before they presented again with an epithelial defect and a stromal infiltrate suggestive of a microbial keratitis, and we propose an immune pathogenesis for the keratitis and uveitis in some of the cases.

\section{Methods}

Eleven patients were identified who had previously been treated for RCE and who presented again with a corneal infiltrate suggestive of a microbial keratitis. This represents all known patients with this condition from an estimated 5800 patient episodes with RCE seen in the casualty department during the 4 year period to January 1995. Once the cases were identified, the clinical records were reviewed. Patients with a history of contact lens wear immediately before presentation or a history of herpetic keratitis were excluded. For each case, the lid margins and conjunctiva were swabbed and the corneal infiltrate was scraped with a 21 gauge needle for Gram stain and incubation on blood agar, brain-heart infusion, and Robertson's cooked meat broth. All eyes were then treated topically with either unpreserved fortified cefuroxime $5 \%$ and gentamicin $1.5 \%$, or with ofloxacin $0.3 \%$. In addition, topical steroids were used in the latter part of the observation period to hasten resolution.

\section{Results}

All 11 eyes had previous episodes of RCE treated with cycloplegia and topical antibiotics and patients were then recommended to use eye ointment prophylactically at night for at 
Table 1 Clinical characteristics of patients

\begin{tabular}{|c|c|c|c|c|c|c|c|}
\hline \multirow[b]{2}{*}{ Patient/sex } & \multirow{2}{*}{$\begin{array}{l}\text { Age at diagnosis } \\
\text { (years) }\end{array}$} & \multirow{2}{*}{$\begin{array}{l}\text { Predisposing } \\
\text { factors }\end{array}$} & \multirow{2}{*}{$\begin{array}{l}\text { Interval since last } \\
\text { erosion (months) }\end{array}$} & \multicolumn{2}{|l|}{ Bacteriology } & \multirow{2}{*}{$\begin{array}{l}\text { Follow up } \\
\text { (months) }\end{array}$} & \multirow{2}{*}{$\begin{array}{l}\text { Final visual } \\
\text { acuity }\end{array}$} \\
\hline & & & & Corea & Lid & & \\
\hline $1 / M$ & 32 & Nil & 7 & Nil & $S$ epidermidis & 14 & $6 / 6$ \\
\hline $2 / \mathrm{F}$ & 22 & Nil & 3 & Nil & Nil & 14 & $6 / 5$ \\
\hline $3 / \mathrm{M}$ & 50 & Trauma & 1.5 & $S$ aureus & $S$ aureus & 19 & $6 / 9$ \\
\hline $4 / M$ & 35 & Nil & 12 & Nil & $S$ aureus & 25 & $6 / 6$ \\
\hline $5 / M$ & 44 & $\begin{array}{l}\text { Trauma } \\
\text { EBMD }\end{array}$ & 48 & Nil & Nil & 25 & $6 / 9$ \\
\hline $6 / F$ & 53 & EBMD & 6 & Nil & Nil & 35 & $6 / 9$ \\
\hline $7 / \mathrm{M}$ & 31 & Trauma & 9 & Nil & Nil & 24 & $6 / 9$ \\
\hline $8 / \mathrm{F}$ & 43 & Trauma & 12 & Nil & Nil & 22 & $6 / 6$ \\
\hline $9 / \mathrm{M}$ & 46 & Nil & 2 & Nil, $S$ aureus ${ }^{\star}$ & Nil, Nil* & 6 & $6 / 9$ \\
\hline $10 / \mathrm{F}$ & 30 & Trauma & 4 & Nil & Nil & 6 & $6 / 9$ \\
\hline $11 / \mathrm{F}$ & 40 & $\begin{array}{l}\text { Trauma } \\
\text { EBMD }\end{array}$ & 1 & Nil & Nil & 8 & $6 / 5$ \\
\hline
\end{tabular}

$\mathrm{EBMD}=$ epithelial basement membrane disease observed on contralateral eye; ${ }^{\star}$ second episode.

least 3 months to reduce the risk of a further recurrence. No patient had received topical antibiotic treatment in the period immediately before the development of a corneal infiltrate, but three were taking an oral tetracycline as treatment for blepharitis.

Each patient had presented again with an acute episode of pain suggestive of a further epithelial breakdown but, on examination, there was an epithelial defect as well as an

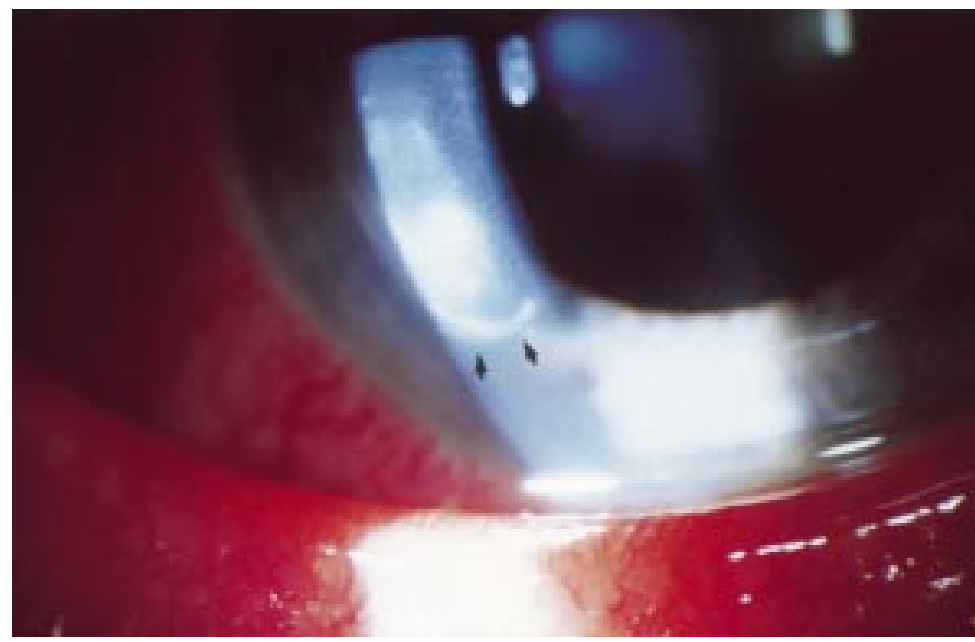

Figure 1 Case 1. Taken 24 hours after presentation. There is a dense stromal infiltrate with an incomplete ring infiltrate inferiorly (arrows). The hypopyon had almost completely resolved and is not demonstrated in this photograph.

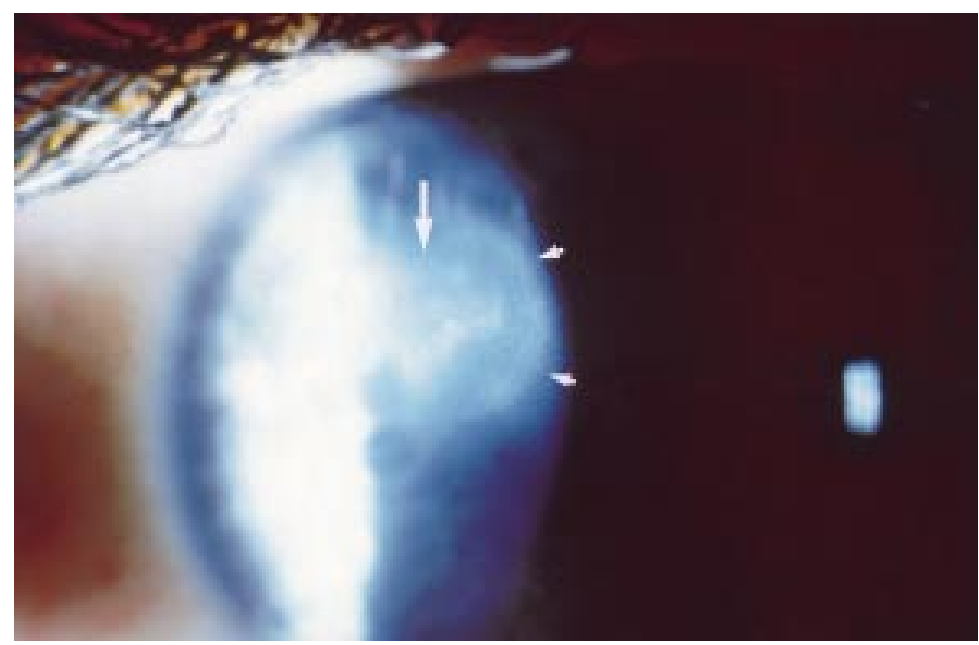

Figure 2 Case 2. The epithelial defect and infiltrate are illustrated (large arrow) with the surrounding ring infiltrate (smaller arrows). intense stromal infiltrate suggestive of microbial keratitis. The clinical features are summarised in Table 1. In all cases there was a marked anterior uveitis with a hypopyon in three eyes, and a surrounding ring of stromal infiltration in four eyes (Figs 1, 2, 3). In six cases the infiltrate resolved on topical antibiotic treatment alone, while five cases also received topical corticosteroid (prednisolone $0.1 \%$, prednisolone $0.3 \%$, or dexamethasone $0.1 \%$ ). All cases were left with a faint anterior stromal scar, but only one patient with rosacea had a recurrence of symptoms of RCE and a further corneal infiltrate during the follow up period for all cases of 6 to 35 months (mean 18 months).

Staphylococcus aureus was isolated from the lids of two patients and $S$ epidermidis was isolated from the lids of one patient. $S$ aureus was isolated from the cornea of two patients (Table 1). Both corneal isolates were fully sensitive to the cefuroxime, gentamicin, and ofloxacin. The bacterial isolation rate $(16 \%)$ is less than the recovery from suspected microbial keratitis unrelated to RCE (44\%) investigated by the corneal and external disease department during the same time period using the same culture techniques.

\section{Discussion}

A number of different inflammatory stimuli such as microbial infection, mechanical or thermal injury, and an immune hypersensitivity response can produce corneal infiltration. It may be difficult using clinical signs to reliably distinguish between the corneal infiltrate caused by infection and an infiltrate caused by a hypersensitivity response, although the management differs significantly. Pain, suppurative discharge, an epithelial defect of $>2 \mathrm{~mm}$, and an anterior chamber reaction are suggestive of a bacterial keratitis, ${ }^{13}$ while a marginal corneal infiltrate with only a minimal epithelial defect or a punctate keratopathy is typical of the sterile keratitis associated with staphylococcal blepharitis. ${ }^{14}$ The mechanisms leading to corneal infiltration differ between the two conditions. In the presence of corneal infection bacterial proteins act as a chemotactic stimulus that direct the migration of neutrophils towards the area of bacterial proliferation, which is followed by an influx of macrophages. Clinically, and in experimental models, marginal 


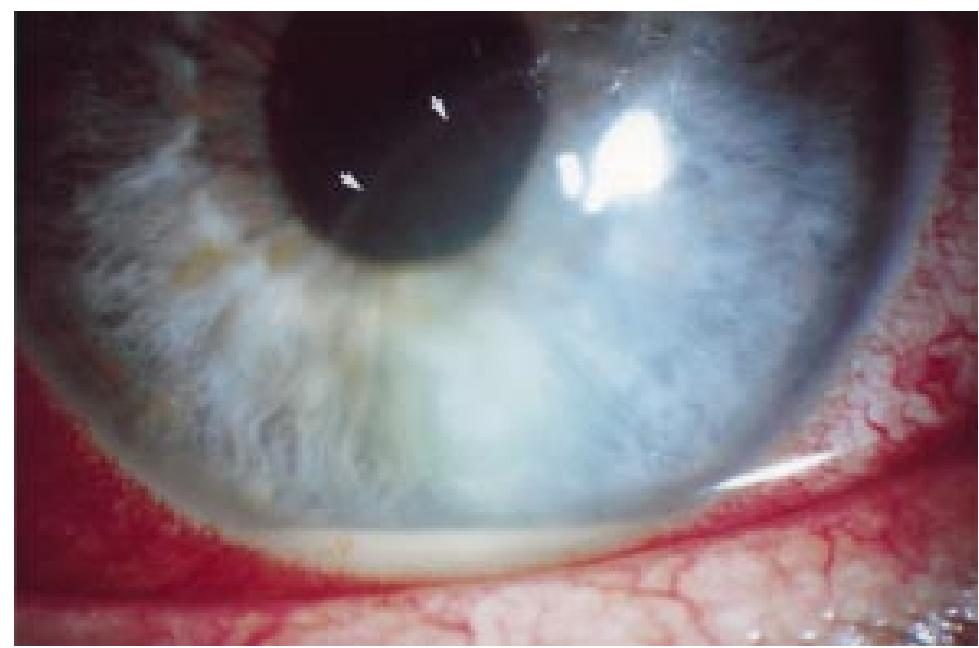

Figure 3 Case 3. An inferiorly situated ulcer is demonstrated with the associated hypopyon. A very faint ring of infiltrate (arrows) appeared to mark the extend of the loose epithelium. Cultures of the corneal and lids grew $S$ aureus.

corneal infiltrates are the result of a $\mathrm{T}$ cell mediated hypersensitivity reaction to staphylococcal cell antigens that attract polymorphonuclear leucocytes and mononuclear cells. ${ }^{15-17}$ Non-infectious, ring-shaped infiltration of the corneal stroma (Wessley ring) has been described in association with various stimuli, including Gram negative bacterial infection ${ }^{18} 19$ and herpes simplex virus infections. ${ }^{20}$ The ring of infiltration is thought to result from complement activation caused either by an intracorneal hypersensitivity reaction against antigens diffusing from a focal source attracting polymorphonuclear leucocytes, or complement may be activated by an antibody independent mechanism via the alternative pathway by bacterial toxin. ${ }^{18}$ Although epithelial injury alone may produce a leucocyte chemotactic factor ${ }^{21}$ dense stromal infiltrates do not develop in most cases of epithelial injury.

The role of epithelial injury in the development of corneal infection is well established. Damage to the epithelium provides adherence sites for bacterial attachment and direct access to the corneal stroma. ${ }^{22}$ Trauma and ocular surface disease are both recognised risk factors for the development of microbial keratitis in temperate regions, accounting for approximately $50 \%$ of cases. ${ }^{23}{ }^{24}$ We therefore speculate that an epithelial erosion not only bypasses the natural resistance of the cornea to infection, but that a large epithelial defect may also permit the enhanced access of bacterial antigens and inflammatory cells into the stroma which, in sensitised individuals, may produce an intense corneal infiltration and uveitis.

We have described 11 patients with a history of RCE who developed a further episode of epithelial breakdown complicated by a dense stromal infiltrate, an anterior uveitis, and an associated hypopyon in some cases. These are clinical features usually associated with microbial keratitis. Despite referral to the specialist corneal service a positive culture was obtained from only two of the 12 episodes, an isolation rate $(16 \%)$ which is less than the current recovery rate from all cases of suspected microbial keratitis seen in the department $(44 \%)$. The severity of the clinical signs did not correlate with the culture result, as hypopyon and ring infiltrate were both seen in patients who were culture positive and in patients who were culture negative. The rapid resolution and favourable outcome despite the clinical appearance suggests that at least in some cases a stromal infiltrate in the presence of a RCE may be the result of an immune response to bacterial antigens analogous to 'sterile' marginal corneal infiltrates. Interestingly, the inflammation may aid adhesion between the epithelium and the stroma, as all 11 patients were symptom free at last follow up. This compares with a recent telephone survey of patients with RCE in which $58 \%$ of 105 patients were still symptomatic 1 year after their initial presentation. ${ }^{25}$

Corneal infiltration is an uncommon complication of RCE. Although a proportion of cases may represent true 'sterile' corneal infiltrates two yielded a positive culture. As we could not distinguish clinically the infected from the non-infected cases, our suggested guidelines for the management of an acute keratitis in patients with the RCE syndrome is to treat all patients as potentially infected, to culture the lesion, and treat intensively with topical fortified antibiotics (gentamicin 1.5\% and cefuroxime $5 \%$ ) or ofloxacin $0.3 \%$. Although topical corticosteroid was only prescribed in five of the patients who were examined in the late study period, we now consider that there is no contraindication to starting topical corticosteroid at the same time as starting the topical antibiotic. ${ }^{26}$

1 Kenyon KR. Recurrent corneal erosion; pathogenesis and treatment. Int Ophthalmol Clin 1979;19:169-93.

2 Brown NA, Bron AJ. Recurrent erosion of the cornea. $\mathrm{BrF}$ Ophthalmol 1976;60:84-95

3 Waring GO, Rodrigues MM, Laibson PR. Corneal dystrophies 1: Dystrophies of the epithelium, Bowman's layer and stroma. Surv Ophthalmol 1978;23:71-122.

4 Messer G, Isakow I, Dabush S. Post traumatic recurrent corneal erosion. Met Pediatr Sys Ophthalmol 1983;7:59-63.

5 Hope-Ross MW, Chell PB, Kervick GN, McDonnell PJ. Hope-Ross MW, Chell PB, Kervick GN, McDonnell PJ. Recurrent.

6 Wood TO, McLaughlin BJ. Recurrent erosion. Int Ophthalmol Clin 1988;28:83-93.

7 Williams R, Buckley R. Pathogenesis and treatment of recurrent corneal erosion. BrF Ophthalmol 1985;69:435-7.

8 Luxenberg $\mathrm{MN}$, Green K. Reduction of corneal oedema with topical hyperosmotic agents. Am $\mathcal{f}$ Ophthalmol 1971;71:847-53.

9 Jaanus S. Topical hyperosmotic agents. In: Bartlett JD, Jaanus SD. Clinical ocular pharmacology. 2nd ed. Stoneham, MA: Butterworths, 1989:277.

10 Shoch DE, Stock EL, Schwartz AE. Stromal keratitis complicating anterior membrane dysrophy. Am $\mathcal{f}$ Ophthalmol 1985;100:199-201.

11 Luchs JI, D'Aversa G, Udell IJ. Ulcerative keratitis associated with spontaneous corneal erosions. Invest Ophthalmol Vis Sci (Suppl) 1995;36:S40.

12 Hykin PG, Foss AE, Pavesio C, Dart JKG. The natural history and management of recurrent corneal erosion: a prospective randomised trial. Eye 1994;8:35-40.

13 Stein RM, Clinch TE, Cohen EJ, Genvert GI, Arentsen JJ, Laibson PR. Infected vs sterile infiltrates in contact lens wearers. Am f Ophthalmol 1988;105:632-6.

14 Chignell AH, Easty DL, Chesterton JR, Thomsitt J. Marginal ulceration of the cornea. $\mathrm{Br} f$ Ophthalmol 1970;54:433-40.

15 Thygeson P. Marginal corneal infiltrates and ulcers. Trans Am Acad Ophthalmol Otolaryngol 1947;51:198-207.

16 Mondino BJ, Kowalski R, Ratajczak HV, Petes J, Cutler SB, Mondino BJ, Kowalski R, Ratajczak HV, Petes J, Cutler SB,
Bronw SI. Rabbit model of phlyctenulosis and catarrhal infiltrates. Arch Ophthalmol 1981;99:891-5. 
17 Ficker L, Seal D, Wright P. Staphylococcal infection and the limbus: study of the cell-mediated immune response. Eye limbus: study of

18 Mondino BJ, Rabin BS, Kessler E, Gallo J, Brown SI. Corneal rings with Gram-negative bacteria. Arch Ophthalmol 1977; 95:2222-5

19 Belmont JB, Ostler HB, Dawson CR, Schwab I, Dulay D. Noninfectious ring-shaped keratitis associated with Pseudomonas aeruginosa. Am f Ophthalmol 192;93:33-41.

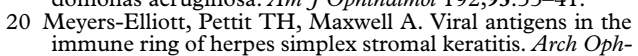
thalmol 1980;98:897-904

21 Grabner G, Luger TA, Smolin G, Oppenheim JJ. Corneal epithelial cell-derived thymocyte-activating factor (CETAF). Invest Ophthalmol Vis Sci 1982;23:757-763.
22 Stern GA, Weitzenkorn D, Valeti J. Adherence of Pseudomonas aeruginosa to the mouse cornea. Arch Ophthalmol domonas aeruginosa

23 Dart JKG. Predisposing factors in microbial keratitis: the significance of contact lens wear. Br $\mathcal{F}$ Ophthalmol 1988;72: 926-30.

24 Gudmundsson OG, Ormerod LD, Kenyon KR, Glynn RJ, Baker AS, Haaf J, et al. Factors influencing predilection and outcome in bacterial keratitis. Cornea 1989;8:115-21

25 Heyworth P, Morlet N, Rayner SR, et al. The natural history of recurrent erosion syndrome. A 48 month prospective follow-up of a cohort of 117 patients. Invest Ophthalmol Vis Sci (Supplement) 1996;37:S703.

26 Allan BDS, Dart JKG. Strategies for the management of microbial keratitis. Br f Ophthalmol 1995;79:777-86. 